\title{
Comparative Effects of Silver Nanoparticles, Sucrose and Sodium Chloride as Osmotic Solutions for Tomato Slices: Antioxidant Activity, Microbial Quality and Modelling with Polynomial Regression Model
}

\author{
Luqmon Azeez $^{\mathrm{a}, *(1 \mathrm{D})}$, Agbaje Lateef ${ }^{\mathrm{b}}$ (D), Abideen A. Wahab ${ }^{\mathrm{c}}$, \\ Ayoade L. Adejumo a and Kawthar Raji ${ }^{\mathrm{a}}$ \\ ${ }^{1}$ Department of Chemical Sciences, Osun State University, Osogbo, Nigeria. \\ ${ }^{2}$ Nanotechnology Research Group $\left(\mathrm{NANO}^{+}\right)$, Laboratory of Industrial Microbiology and Nanobiotechnology, \\ Department of Pure and Applied Biology, Ladoke Akintola University of Technology, PMB 4000, Ogbomoso, Nigeria. \\ ${ }^{3}$ Department of Biological Sciences, Osun State University, Osogbo, Nigeria. \\ Received 2 May 2018, revised 8 January 2019, accepted 16 January 2019.
}

\begin{abstract}
This study has reported comparative effects of silver nanoparticles (AgNPs), sucrose and sodium chloride as osmotic solutions on antioxidant activity and microbial quality of $\mathbf{1 0} \mathrm{mm}$ tomato slices. $40 \mathrm{~g}$ of tomato slices were dehydrated osmotically (OD) at different temperatures $\left(60,70\right.$ and $\left.80^{\circ} \mathrm{C}\right)$ and time $(30,60,90,120150$ and $180 \mathrm{~min})$. Water loss, solid impregnation, water and solid diffusivities of tomato slices were found to increase with increase in solution temperatures and concentrations with AgNPs having the greatest influence. Antioxidant activities using 2,2-diphenyl-1-picrylhydrazyl increased with increase in solution concentrations but decreased with increase in temperature. Three-way ANOVA $\left(R^{2}=0.998\right)$ revealed additive statistically significant effects of osmotic agents, concentrations and temperatures on antioxidant activity; $F_{(8,54)}=67.854, P=0.00$. Polynomial regression analysis with response surface methodology validated experiments such that for each unit increase in concentration and temperature, antioxidant activity increased with good coefficients of determination; sucrose $\left(R^{2}=0.87\right), N a C l,\left(R^{2}=0.89\right)$ and AgNPs $\left(R^{2}=0.91\right)$. Potato dextrose and nutrient agars were used for isolating and identifying microorganisms in OD tomato slices. Tomato slices dehydrated with AgNPs had the highest microbial inhibition of fungi with growth occurring after 7 days, unlike in treatments with sucrose and $\mathrm{NaCl}$ where fungal growth appeared after 2 and 5 days, respectively. Aspergillus niger was the most prevalent fungus. It can be concluded that AgNPs may serve as a viable means to dehydrate and preserve tomatoes without loss of antioxidant activity.
\end{abstract}

KEYWORDS

Osmotic dehydration, polynomial regression, response surface, antioxidant activity, three-way ANOVA, silver nanoparticles.

\section{Introduction}

Tomatoes (Lycopersicon esculentum) are essentially beneficial vegetables containing polyphenols, carotenoids, vitamins and minerals that can be either eaten raw or processed.$^{1-5}$ Studies have established that consumption of tomatoes with inverse correlation with risk of degenerative diseases. This stems from the antioxidant, anti-inflammatory and anti-cancer properties of bioactive compounds contained in tomatoes. ${ }^{4,6}$ Quality of tomatoes is affected by microbial degradation because of high moisture content which aids rottenness and allows potent mycotoxin producers such as Aspergillus, Trichoderma, Fusarium, Curvularia and Penicillium species to thrive, thus making rotten tomatoes hazardous for consumption. ${ }^{7-10}$

Different dehydration processes have been reported for preserving tomatoes; however, some of these methods, especially those involving thermal treatment, degrade bioactive components in tomatoes. ${ }^{11,12}$ Thus, the need to use osmotic dehydration (OD) which retains antioxidant activity of foods better than thermal processes.

* To whom correspondence should be addressed.

E-mail: luqman.azeez@uniosun.edu.ng
Osmotic dehydration (OD) is a method of preservation that involves partial moisture loss from food materials to improve their shelf-lives. It saves energy and prevents oxidative browning. ${ }^{13-16}$ It is done by immersing food materials either in whole or units into hypertonic solution which allows diffusion of moisture from the food material into the solution concurrently with solid impregnation into the food material. ${ }^{10,17-22}$ This transfer could also be accompanied by leaching of organic acids, sugars, salts, fragrances, colourants and minerals from the food materials into the solution. ${ }^{16,23}$ Sugar and salt solutions are usually employed with sucrose and sodium chloride as the mostly used. ${ }^{16,17,24-27}$

Salt and sucrose solutions preserve food materials and equally impede the growth of microorganisms which cause rottenness by weakening the structure of microbial enzymes involved in deterioration. Use of mixtures of these solutions like sucrosesodium chloride has also been reported by some authors with advantages. ${ }^{1724-27}$ However, none of these osmotic solutions have been reported to improve antioxidant activities of food materials. Furthermore, several studies have reported use of nanoparticles, especially silver nanoparticles, for food processing and preservation. ${ }^{51-53}$ Silver nanoparticles (AgNPs) offer food 
industries range of approaches to improve quality, shelf-life and nutritional composition of food. Biogenic AgNPs have been reported with activity to inhibit growth of bacteria, moulds and yeasts as well as having ability to boost antioxidant activity due to its high antioxidant activity. AgNPs is used as antibacterial agent in food and food packaging due to their low volatility including stability at high temperature. Though there is dearth of information on the toxicity of AgNPs from food consumption but concerns about the potential toxicity likely due to release of silver ion $\left(\mathrm{Ag}^{+}\right)$exist. ${ }^{28-36,54,55}$ However, results of Yekeen et al..$^{56}$ show that AgNPs has minimal effects on the inhibition of Allium cepa cells. Consequently, a comparative study with biogenic silver nanoparticles (AgNPs) synthesized from extracts of cocoa beans (CBE) as an alternative to constantly used osmotic solutions was undertaken in this study.

Mass transfer kinetic parameters play major roles in determining the extent of preservation, water loss, solid impregnation as well as antioxidant activity status of food materials during OD as functions of immersion time, solution concentrations and temperatures. Many researchers have studied effects of different osmotic parameters but none has predicted their effects on improvement of antioxidant activity of food materials.

Polynomial regression model is a statistical modelling tool for investigating the relationships between variables to provide estimates of values of the dependent variable by using the prediction equation. It is highly useful when relationship between dependent and independent variables is curvilinear. It consists of successive power terms. It is an effective and flexible curve fitting technique. ${ }^{37,38}$

In this study, effects of concentrations of osmotic solution and operating temperature were fitted to quadratic equations generated from modelled antioxidant activities of osmotic agents to provide estimates of antioxidant activity at the optimum conditions.

\section{Materials and Methods}

\subsection{Reagents}

Analar grade chemicals, 2,2-diphenyl-1-picrylhydrazyl $(\mathrm{DPPH}), \mathrm{CH}_{3} \mathrm{OH}, \mathrm{NaCl}$ and sucrose, were purchased from Sigma-Aldrich, Germany.

\subsection{Osmotic Solutions, Biosynthesis and Characterization of Silver Nanoparticles (AgNPs)}

AgNPs used in this study were biologically synthesized using the extract of cocoa beans as reported by Azeez et al. ${ }^{28}$ The scheme for biosynthesis is illustrated in Fig. 1. The biosynthesized AgNPs were characterized by UV-Vis spectroscopy, Fourier transform infrared spectroscopy (FTIR) and transmission electron microscopy (TEM) following standard procedures. Different concentrations of 25, 50, and 75 ppm of AgNPs, sucrose and $\mathrm{NaCl}$ solutions were prepared.

\subsubsection{Osmotic Treatment}

Raw tomatoes (Hausa tomatoes varieties) were purchased from Sasa local market Osogbo, Osun State, Nigeria. They were rinsed, blotted and cut into spherical slices of $3 \mathrm{~cm} \times 10 \mathrm{~mm}$ (diameter $\times$ thickness). Then, $40 \mathrm{~g}$ of tomato slices were immersed into $100 \mathrm{~mL}$ of 25, 50, $75 \mathrm{ppm}$ of AgNPs, sucrose and $\mathrm{NaCl}$ in a $2 \mathrm{~L}$ stainless steel container placed in a water bath. The bath was maintained at 60,70 and $80^{\circ} \mathrm{C}$ for $30,60,90,120,150$ and $180 \mathrm{~min}$. Tomato slices were removed $30 \mathrm{~min}$ interval, blotted and weighed. Moisture content was determined at $80^{\circ} \mathrm{C}$ for $24 \mathrm{~h}$ in an oven (Uniscope SM9053 Surgifield Medicals England). The control samples were oven-dried at 60,70 , and $80^{\circ} \mathrm{C}$.

\subsection{Mass Transfer Kinetics During Osmotic Dehydration}

\subsubsection{Water Loss and Solid Gain}

Water loss (WL) and solid gain (SG) during osmotic dehydration of tomato slices are calculated using Equations 1 and 2.

$$
\begin{aligned}
\mathrm{WL} & =\frac{\left(\mathrm{M}_{\mathrm{o}}-\mathrm{m}_{\mathrm{o}}\right)(\mathrm{M}-\mathrm{m})}{\mathrm{m}_{\mathrm{o}}} \\
\mathrm{SG} & =\frac{\left(\mathrm{m}-\mathrm{m}_{\mathrm{o}}\right)}{\mathrm{m}_{\mathrm{o}}}
\end{aligned}
$$

where WL is the water loss, $S G$ is solid gain, $M_{o}$ is the initial mass of fresh tomato slices $(\mathrm{g}), \mathrm{M}$ is the mass of tomato slices after time $(\mathrm{t})$ of osmotic dehydration $(\mathrm{g}), \mathrm{m}$ is the dry mass of tomato slices $(\mathrm{g})$ after time $(\mathrm{t})$ of osmotic dehydration, and $\mathrm{m}_{\mathrm{o}}$ is the initial dry mass of tomato slices $(\mathrm{g})$.

\subsubsection{Effective Diffusivities and Activation Energy}

Fick's model is usually employed to describe the mass transfer involved in dehydration and impregnation during osmotic dehydration. ${ }^{23,39}$ Equations 3-6 were used to calculate moisture ratio, solid ratio, effective diffusivities and activation energy.

$$
\begin{aligned}
& \mathrm{MR}=\frac{8}{\pi^{2}} \sum_{\mathrm{n}=0}^{\infty} \frac{1}{2 \mathrm{n}-1} \mathrm{e}^{\left(\frac{-(2 \mathrm{n}-1)^{2} \pi^{2} \mathrm{D}_{\text {ew }}}{4 \mathrm{~L}^{2}}\right)} \\
& \mathrm{SR}=\frac{8}{\pi^{2}} \sum_{\mathrm{n}=0}^{\infty} \frac{1}{2 \mathrm{n}-1} \mathrm{e}^{\left(\frac{-(2 \mathrm{n}-1)^{2} \pi^{2} \mathrm{D}_{\mathrm{es}}}{4 \mathrm{~L}^{2}}\right)} \\
& \mathrm{D}_{\mathrm{ew}}=\mathrm{D}_{\mathrm{es}}=\frac{- \text { slope } 4 \mathrm{~L}^{2}}{\pi^{2}}
\end{aligned}
$$

$D_{\text {ew }}$ and $D_{\text {es }}$ are fitted to Arrhenius Equation (13) to calculate activation energy

$$
\mathrm{D}_{\mathrm{ew}}=\mathrm{D}_{\mathrm{es}}=\mathrm{D}_{0} \mathrm{e}^{\frac{\mathrm{E}_{\mathrm{a}}}{\mathrm{RT}}}
$$

where MR is moisture ratio, $\mathrm{SR}$ is solid ratio, $\mathrm{D}_{\mathrm{ew}}$ is the effective diffusivity of water loss $\left(\mathrm{m}^{2} \mathrm{~s}^{-1}\right), \mathrm{D}_{\mathrm{es}}$ is the effective diffusivity of solid $\left(\mathrm{m}^{2} \mathrm{~s}^{-1}\right)$, $\mathrm{t}$ is the time $(\mathrm{s}), \mathrm{L}$ is the slice half thickness $(\mathrm{m}), \mathrm{D}_{0}$ is the Arrhenius constant $\left(\mathrm{m}^{2} \mathrm{~s}^{-1}\right), \mathrm{E}_{\mathrm{a}}$ is the activation energy $\left(\mathrm{KJ} \mathrm{mol}^{-1}\right), \mathrm{R}$ is the universal gas constant $\left(8.314 \mathrm{~J} \mathrm{~mol}^{-1} \mathrm{~K}^{-1}\right)$, and $\mathrm{T}$ is the absolute temperature $(\mathrm{K})$. The slope of $\ln \left(\mathrm{D}_{\mathrm{ew}}\right.$ or $\left.\mathrm{D}_{\mathrm{es}}\right)$ against $\frac{1}{\mathrm{~T}}$ is the activation energy.

\subsection{Extraction and Determination of Antioxidant Activities in Tomato Slices}

Dried osmotically dehydrated and oven-dried tomatoes were blended with Crown star electric blender to powder. Then, $1 \mathrm{~g}$ of the powdered tomato samples was extracted with $100 \mathrm{~mL}$ of $70 \%$ aqueous methanol for $2 \mathrm{~h} 30 \mathrm{~min}$, filtered and dried in a water bath. Different methanolic concentrations of the extract were prepared for the determination of antioxidant activities using the stable radical DPPH method as previously reported by Azeez et al. ${ }^{29}$ and calculated using Equation 7.

$$
\text { Inhibition }(\%)=\frac{\left(\mathrm{A}_{\text {control }}-\mathrm{A}_{\text {sample }}\right)}{\mathrm{A}_{\text {control }}} \times 100
$$

where $\mathrm{A}_{\text {control }}$ and $\mathrm{A}_{\text {sample }}$ are absorbance values of the control and extract, respectively.

\subsection{Polynomial Regression Modelling of Optimum \\ Conditions for Antioxidant Activity}

Polynomial is a form of linear regression that predicts a single dependent variable $(y)$ by expressing the independent variables $(\mathrm{x})$ in $\mathrm{i}^{\text {th }}$ order polynomial. Different powers of the $\mathrm{x}$ variables are sequentially added to polynomial equation to significantly increase $\mathrm{R}^{2}$. The basic polynomial regression model of a depend- 

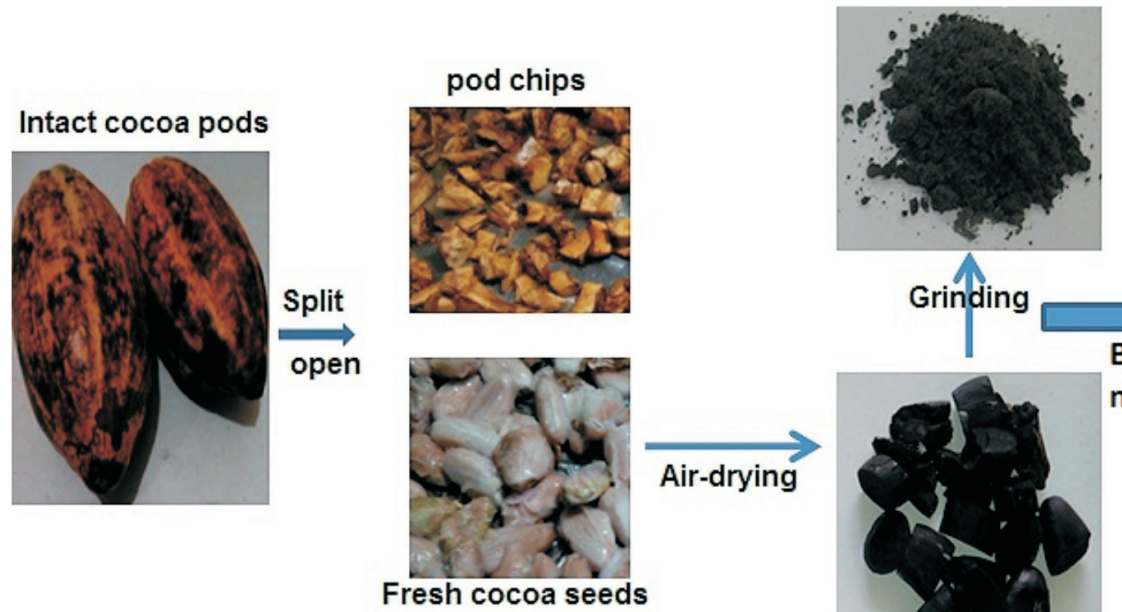
Biosynthesis of silver
nanoparticles
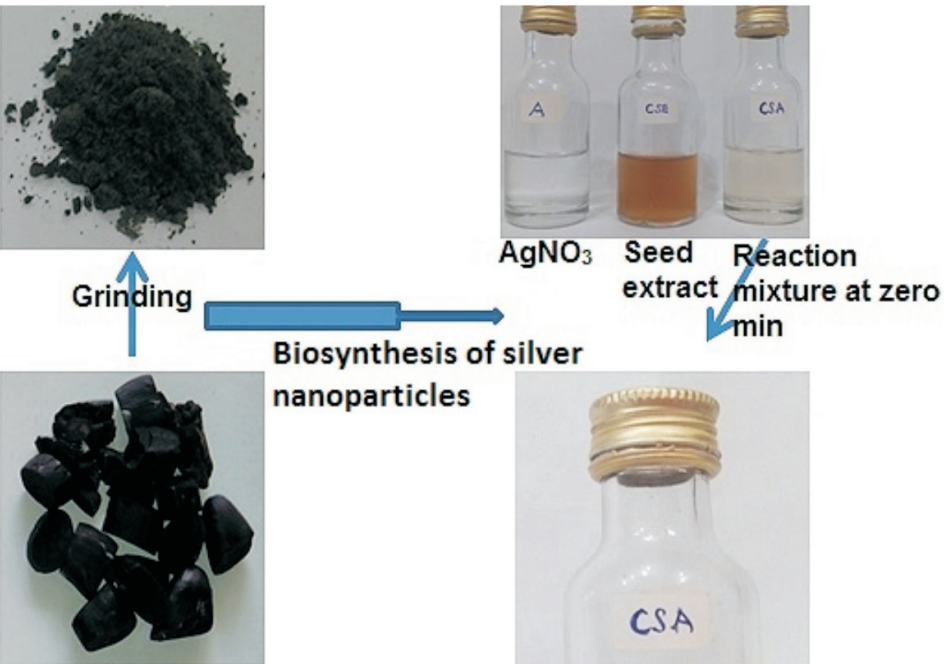

Dried cocoa seeds

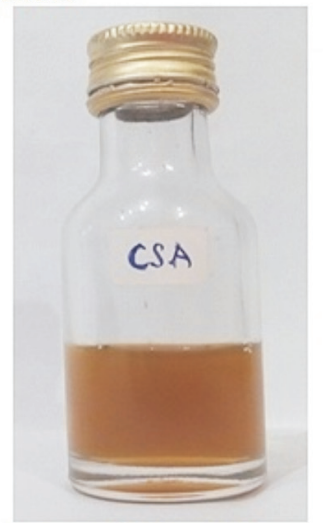

Biosynthesized silver nanoparticles at 10 minutes of reaction

Figure 1 Scheme for the biogenic synthesis of AgNPs using the pod extract of cocoa.

ent variable $y$ on a set of $x$ independent variables can be expressed as

$$
y=\beta_{0}+\beta_{1} x+\beta_{2} x^{2}
$$

where $\beta_{0}, \beta_{1}, \beta_{2}$ are the intercept of the regression surface, linear effects and quadratic effect parameters, respectively.

When two or more independent variables are fitted, secondorder polynomial regression model is used, therefore the methodology of response surface methodology is used to fit such models and helps in estimating values of the dependent. ${ }^{37,38}$

\subsection{Microbial Quality of Osmotically Dehydrated Tomato Slices}

\subsubsection{Isolation and Identification of Microorganisms}

Potato dextrose agar (PDA) and nutrient agar were the growth media prepared for microbial isolation. Solutions of tomato samples osmotically dehydrated with sucrose, sodium chloride and AgNPs were prepared by aseptically introducing $1 \mathrm{~g}$ of dried tomato samples into $10 \mathrm{~mL}$ of distilled water and was then serially diluted to $10^{-3}, 10^{-5}$ and $10^{-7}$. Then, $1 \mathrm{~mL}$ each from the selected tube was introduced to the prepared media (PDA and nutrient agar), which were incubated at 25 and $37^{\circ} \mathrm{C}$ for seven days for the growth of fungi and bacteria. Isolates obtained were purified to obtain pure cultures, identified and characterized based on their colonial and morphological characteristics. The microscopic features of fungi were compared with fungal compendium. ${ }^{40}$

\subsection{Model Fitting and Analysis of Statistical Significance}

Data of antioxidant activity are presented as mean \pm standard deviation of three replicates. A three-way ANOVA was conducted to reveal the effects of osmotic dehydration conditions on antioxidant activity at $95 \%$ confidence level using SPSS software (IBM SPSS Statistics 20, Chicago, USA).
Matlab R2014a was used for data analysis, polynomial model building, and experimental design. Analysis of variance and response surface analysis were employed to determine the regression coefficients and statistical significance of the model terms and to fit the polynomial models.

Similarities between predicted polynomial regression and experimental antioxidant activities were determined by correlation coefficient $\left(R^{2}\right)$

\section{Results and Discussion}

\subsection{Biogenic Synthesis of AgNPs}

As previously reported by Azeez et al. ${ }^{28}$, extract of cocoa beans facilitated the bioformation of AgNPs within 10 min of reaction under benign conditions leading to development of brown colloidal solution which had maximum absorption at $438.5 \mathrm{~nm}$ (Fig. 2). The nearly spherical AgNPs were polydispersed with size distribution of 8.96-54.22 nm (Fig. 2). The AgNPs displayed antimicrobial activities against drug-resistant bacteria by inhibiting their growth to the tune of $10-14 \mathrm{~mm}$. It also improved antibacterial activities of some antibiotics by $42.9-100 \%$ through synergy, and inhibited bacterial and fungal growth when used as additive in paint. Furthermore, the AgNPs demonstrated larvicidal activities against larvae of Anopheles gambiae, and also prevented coagulation of blood. . $^{2,30-32}$

\subsection{Effects of Different Osmotic Agents, Concentrations,} Temperatures and Immersion Time on Water Loss and Solid Gain of Tomato Slices

The effects of time of immersion, solution concentrations and temperatures during OD on water loss (WL) of tomato slices in different osmotic agents are presented in Fig. 3 while their effects on solid gain (SG) are presented in Fig. 4. Generally, WL and SG increased with increased immersion time, concentrations and temperatures of osmotic solution with the trend of 

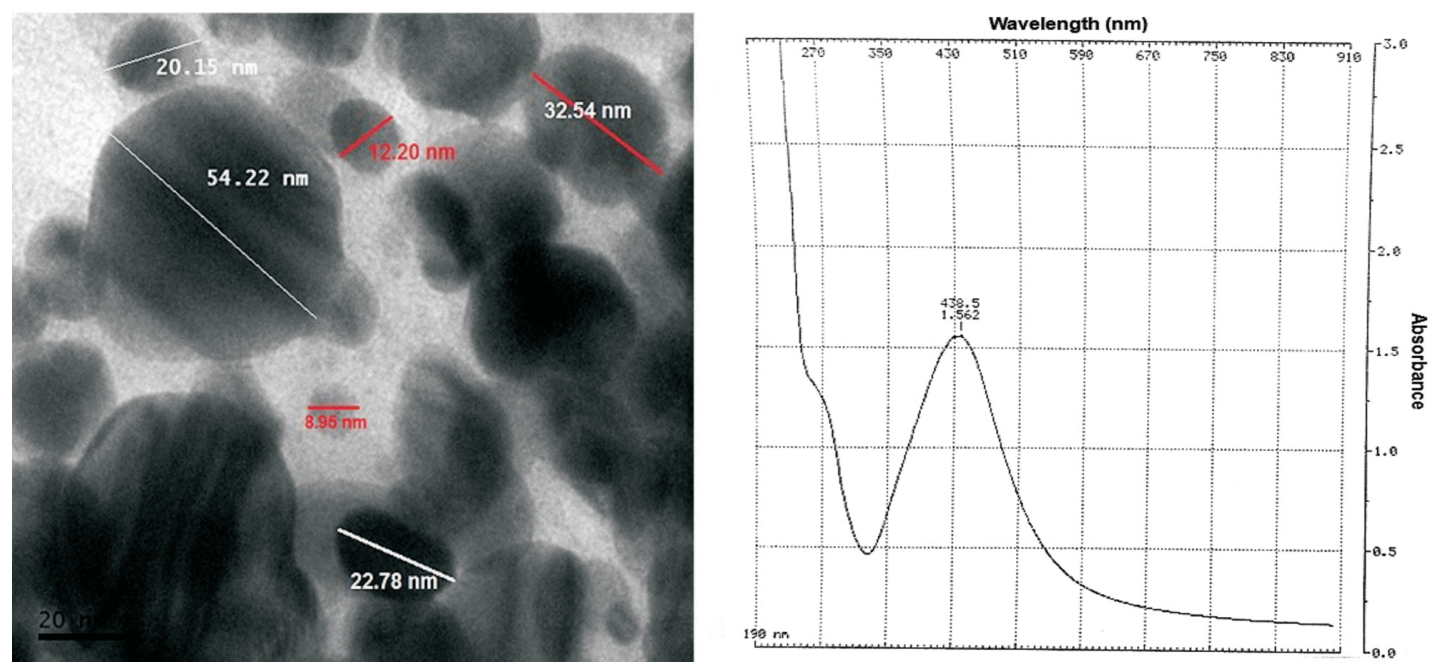

Figure 2 TEM micrograph and UV-Vis spectrum of biosynthesized AgNPs.

increase as function of osmotic agents ranging from AgNPs $>$ $\mathrm{NaCl}>$ sucrose for WL and AgNPs $>$ sucrose $>\mathrm{NaCl}$ for SG. This agrees with the acceleration of diffusion process owing to the ability of temperature and immersion time to lower viscosity of osmotic solution while increase in osmotic solution concentra- tion increase the driving potential. ${ }^{13,16,23,27,41,42}$ Greatest influence of AgNPs on WL and SG could be due to its nanostructure which enhanced diffusion leading to higher water loss and better solid impregnation. ${ }^{43}$

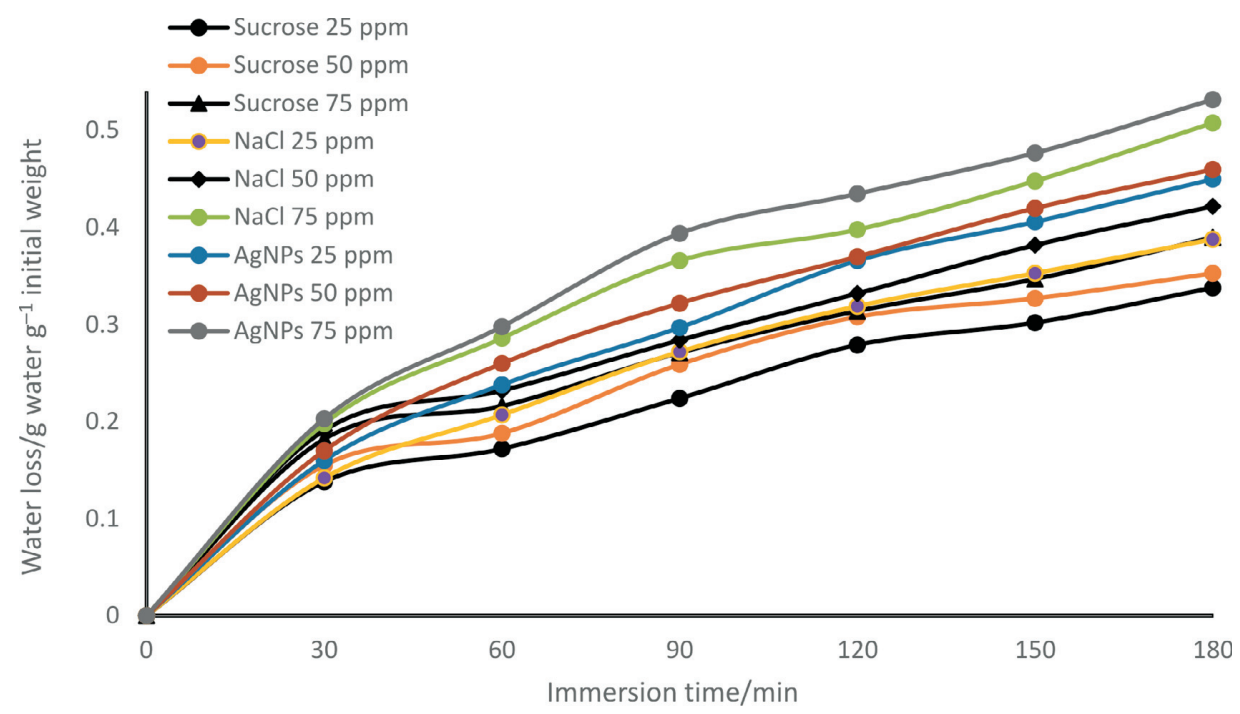

Figure 3 Effects of osmotic solutions, solution concentrations and immersion time on water loss from $10 \mathrm{~mm}$ tomato slices at $80{ }^{\circ} \mathrm{C}$.

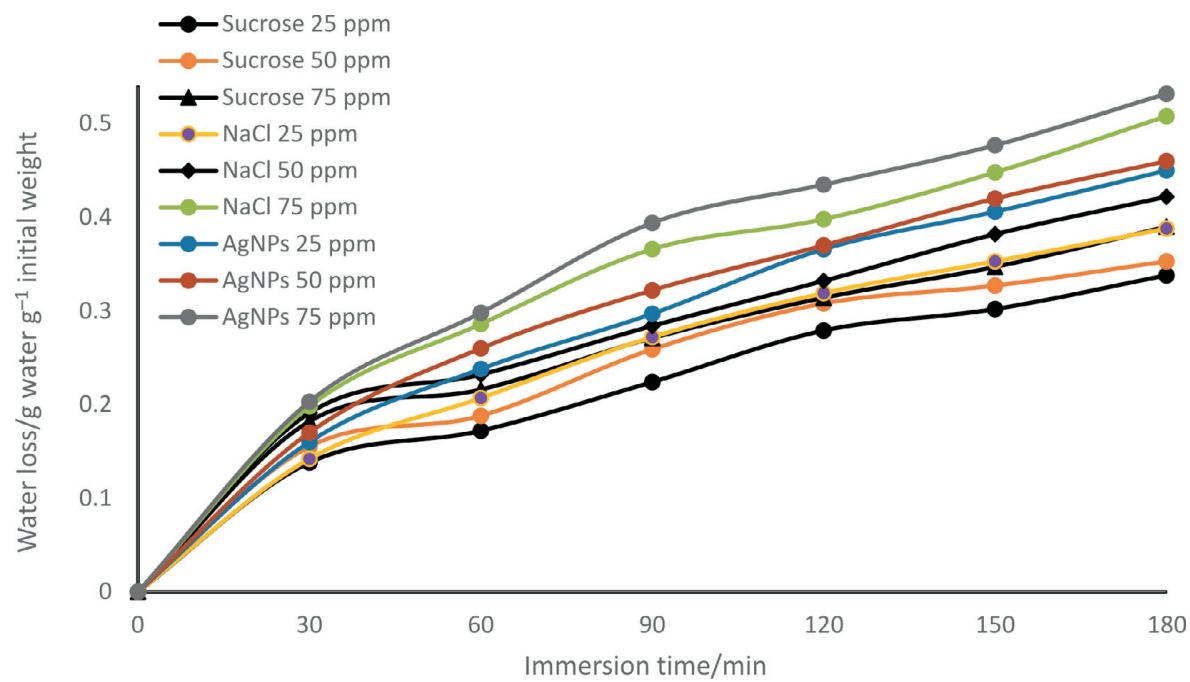

Figure 4 Effects of osmotic solutions, solution concentrations and immersion time on solid gain on $10 \mathrm{~mm}$ tomato slices at $60^{\circ} \mathrm{C}$. 
3.2.1. Effects of Different Osmotic Agents, Concentrations and Temperatures on Water and Solid Diffusivities

WL and SG data were fitted to Fick's diffusion model to evaluate effective diffusion coefficients $\left(\mathrm{D}_{\text {eff }}\right)$ and activation energy for $10 \mathrm{~mm}$ tomato slices osmotically dehydrated with $25-75 \mathrm{ppm}$ AgNPs, sucrose and $\mathrm{NaCl}$ from $60-80^{\circ} \mathrm{C}$. Tables 1 and 2 show the values of effective diffusion coefficients calculated using Equations 11-13 for $10 \mathrm{~mm}$ tomato slices in different osmotic solutions. Water diffusivities $\left(\mathrm{WD}_{\text {eff }}\right)$ ranged from $5.76 \times 10^{-8}$ to $6.74 \times 10^{-8}$ for AgNPs, $5.10 \times 10^{-8}$ to $6.16 \times 10^{-8}$ for sucrose and $4.83 \times 10^{-8}$ to $6.55 \times 10^{-8}$ for $\mathrm{NaCl}$. Solid diffusivities $\left(\mathrm{SD}_{\text {eff }}\right)$ ranged from $9.70 \times 10^{-8}$ to $1.25 \times 10^{-7}$ for AgNPs, $8.20 \times 10^{-8}$ to $1.59 \times 10^{-7}$ for sucrose and $8.33 \times 10^{-8}$ to $2.18 \times 10^{-7}$ for $\mathrm{NaCl}$. It was observed that $\mathrm{WD}_{\text {eff }}$ and $\mathrm{SD}_{\text {eff }}$ increased with increase in temperatures and concentrations of osmotic agents. The increase in $D_{\text {eff }}$ with increase in osmotic medium temperature might be connected to the vapour pressure inside tomato slices which resulted from increased diffusion process and higher porousity as functions of temperature and concentrations. ${ }^{23,44}$ Comparatively, the trend in $\mathrm{WD}_{\text {eff }}$ followed AgNPs $>\mathrm{NaCl}>$ sucrose while the trend in $\mathrm{SD}_{\text {eff }}$ follows $\mathrm{NaCl}>$ Sucrose $>$ AgNPs. The values of diffusion coefficients in this study are similar to results in references $23,27,41$ and 42.

\subsubsection{Effects of Different Osmotic Agents, Concentrations and Temperatures on Activation Energy}

Activation energies for water and solid diffusivities calculated using Fick's model are presented in Table 3. Activation energy reduced with increase in concentration of osmotic solution. The trend of activation energy with respect to osmotic solution follows AgNPs < sucrose $<\mathrm{NaCl}$. Lower activation energy of AgNPs compared to other solutions shows that in osmotic dehydration using AgNPs required lower energy to initiate diffusion process $^{16,44,45}$ and this could be better alternative

\subsection{Effects of Osmotic Agents, Concentrations and Temperatures on Antioxidant Activity of Tomatoe Slices}

The results of antioxidant activity of $10 \mathrm{~mm}$ tomato slices subjected to different osmotic dehydrations conditions are presented in Table 4. Antioxidant activities increased with increase in concentration of osmotic solution but reduced with increase in temperature. The trend of effects of osmotic agents on antioxidant activity in decreasing order followed AgNPs > sucrose $>\mathrm{NaCl}$. This is in consonance with water loss and solid impregnation abilities of the agents. This shows that AgNPs had higher ability to improve antioxidant activity. Comparing antioxidant activities of osmotically dehydrated with vacuum ovendried (control) tomato slices, OD treated tomato samples with AgNPs and sucrose had higher antioxidant activities than the control at $60^{\circ} \mathrm{C}$, lower at other temperatures except for AgNPs at $70{ }^{\circ} \mathrm{C}$. Osmotic dehydration using AgNPs preserved and improved antioxidant activity of tomato slices better than other solution. Three-way ANOVA $\left(\mathrm{R}^{2}=0.998\right)$ conducted on the results revealed additive statistically significant effects of osmotic agents, concentrations and temperatures on antioxidant activity, $F_{(8,54)}=67.854, P=0.00$. Additive statistically significance

Table 1 Water diffusivities for tomato slices osmotically dehydrated at different temperatures and osmotic concentrations for different osmotic agents.

\begin{tabular}{|c|c|c|c|c|c|c|c|c|c|}
\hline \multirow[t]{3}{*}{ Solution: } & \multicolumn{3}{|c|}{ AgNPs } & \multicolumn{3}{|c|}{ Sucrose } & \multicolumn{3}{|c|}{$\mathrm{NaCl}$} \\
\hline & \multicolumn{3}{|c|}{ Concentration/ppm } & \multicolumn{3}{|c|}{ Concentration/ppm } & \multicolumn{3}{|c|}{ Concentration/ppm } \\
\hline & 75 & 50 & 25 & 75 & 50 & 25 & 75 & 50 & 25 \\
\hline \multicolumn{10}{|l|}{ Temperature } \\
\hline $60^{\circ} \mathrm{C}$ & $6.34 \mathrm{E}-08$ & $6.20 \mathrm{E}-08$ & $5.76 \mathrm{E}-08$ & 5.10E-08 & 5.12E-08 & $5.15 \mathrm{E}-08$ & 5.64E-08 & 4.83E-08 & 5.87E-08 \\
\hline $70{ }^{\circ} \mathrm{C}$ & 6.09E-08 & $6.06 \mathrm{E}-08$ & 5.97E-08 & $5.86 \mathrm{E}-08$ & 5.54E-08 & $5.36 \mathrm{E}-08$ & $5.89 \mathrm{E}-08$ & $6.18 \mathrm{E}-08$ & 5.97E-08 \\
\hline $80^{\circ} \mathrm{C}$ & $6.74 \mathrm{E}-08$ & 6.33E-08 & $6.11 \mathrm{E}-08$ & $6.16 \mathrm{E}-08$ & 5.74E-08 & 5.19E-08 & $6.55 \mathrm{E}-08$ & 5.42E-08 & 5.93E-08 \\
\hline
\end{tabular}

Table 2 Solid diffusivities for tomato slices osmotically dehydrated at different temperatures and osmotic concentrations for different osmotic agents.

\begin{tabular}{|c|c|c|c|c|c|c|c|c|c|}
\hline \multirow[t]{3}{*}{ Solution: } & \multicolumn{3}{|c|}{ AgNPs } & \multicolumn{3}{|c|}{ Sucrose } & \multicolumn{3}{|c|}{$\mathrm{NaCl}$} \\
\hline & \multicolumn{3}{|c|}{ Concentration/ppm } & \multicolumn{3}{|c|}{ Concentration/ppm } & \multicolumn{3}{|c|}{ Concentration/ppm } \\
\hline & 75 & 50 & 25 & 75 & 50 & 25 & 75 & 50 & 25 \\
\hline \multicolumn{10}{|l|}{ Temperature } \\
\hline $60^{\circ} \mathrm{C}$ & $1.20 \mathrm{E}-07$ & $9.71 \mathrm{E}-08$ & $9.70 \mathrm{E}-08$ & $1.59 \mathrm{E}-07$ & $8.20 \mathrm{E}-08$ & $1.05 \mathrm{E}-07$ & $1.31 \mathrm{E}-07$ & 8.19E-08 & 8.10E-08 \\
\hline $70{ }^{\circ} \mathrm{C}$ & $1.25 \mathrm{E}-07$ & $1.22 \mathrm{E}-07$ & $1.03 \mathrm{E}-07$ & $1.23 \mathrm{E}-07$ & 1.17E-07 & $1.05 \mathrm{E}-07$ & $1.52 \mathrm{E}-07$ & 1.13E-07 & 8.33E-08 \\
\hline $80^{\circ} \mathrm{C}$ & $1.23 \mathrm{E}-07$ & $1.06 \mathrm{E}-07$ & $1.05 \mathrm{E}-07$ & $1.15 \mathrm{E}-07$ & $1.11 \mathrm{E}-07$ & $1.06 \mathrm{E}-07$ & $2.18 \mathrm{E}-07$ & $1.32 \mathrm{E}-07$ & $1.13 \mathrm{E}-07$ \\
\hline
\end{tabular}

Table 3 Activation energy $/ \mathrm{kJ} \mathrm{mol}^{-1}$ for tomato slices osmotically dehydrated at different temperatures and osmotic concentrations.

\begin{tabular}{|c|c|c|c|c|c|c|}
\hline \multirow{2}{*}{$\begin{array}{l}\text { Solution: } \\
\text { Concentration (ppm) }\end{array}$} & \multicolumn{2}{|c|}{ AgNPs } & \multicolumn{2}{|c|}{ Sucrose } & \multicolumn{2}{|c|}{$\mathrm{NaCl}$} \\
\hline & Water diffusivity & Solid diffusivity & Water diffusivity & Solid diffusivity & Water diffusivity & Solid diffusivity \\
\hline 25 & 2.975 & 4.506 & 9.259 & 15.101 & 7.279 & 25.610 \\
\hline 50 & 2.957 & 3.950 & 5.606 & 2.716 & 5.756 & 24.945 \\
\hline 75 & 0.965 & 1.478 & 0.396 & 0.751 & 0.445 & 16.148 \\
\hline
\end{tabular}


Table 4 Antioxidant activity of tomato slices osmotically dehydrated at different temperatures and osmotic concentrations for different osmotic agents.

\begin{tabular}{|c|c|c|c|c|c|c|c|c|c|c|}
\hline \multirow[t]{2}{*}{ Solution } & \multicolumn{3}{|c|}{ AgNPs } & \multicolumn{3}{|c|}{ Sucrose } & \multicolumn{3}{|c|}{$\mathrm{NaCl}$} & \multirow[b]{3}{*}{ Control } \\
\hline & \multicolumn{3}{|c|}{ Concentration/ppm } & \multicolumn{3}{|c|}{ Concentration/ppm } & \multicolumn{3}{|c|}{ Concentration/ppm } & \\
\hline Temp. & 25 & 50 & 75 & 25 & 50 & 75 & 25 & 50 & 75 & \\
\hline $60^{\circ} \mathrm{C}$ & $46.67 \pm 0.24$ & $80.42 \pm 2.14$ & $88.31 \pm 2.32$ & $60.72 \pm 1.07$ & $66.99 \pm 1.67$ & $71.17 \pm 0.34$ & $41.22 \pm 0.48$ & $41.62 \pm 1.56$ & $42.28 \pm 2.95$ & $67.31 \pm 0.77$ \\
\hline $70{ }^{\circ} \mathrm{C}$ & $30.33 \pm 0.58$ & $75.52 \pm 1.96$ & $84.68 \pm 0.36$ & $58.50 \pm 0.35$ & $67.69 \pm 0.16$ & $68.01 \pm 1.84$ & $28.06 \pm 0.09$ & $34.98 \pm 1.15$ & $42.39 \pm 0.41$ & $82.74 \pm 0.02$ \\
\hline $80^{\circ} \mathrm{C}$ & $27.04 \pm 0.04$ & $46.71 \pm 0.39$ & $80.01 \pm 0.01$ & $30.93 \pm 0.22$ & $50.48 \pm 0.56$ & $57.71 \pm 0.87$ & $27.04 \pm 1.08$ & $35.84 \pm 0.12$ & $41.20 \pm 0.06$ & $83.61 \pm 0.13$ \\
\hline
\end{tabular}

Data are presented as mean \pm standard deviation of three replicates.

of binary effects of osmotic agents and concentration gave $F_{(4.54)}=790.449, P=0.00$, osmotic agents and temperatures gave $F_{(4,54)}^{(4,54)}=169.551, P=0.00$, while solution concentrations and temperatures gave $F_{(4,54)}=101.485, P=0.00$.

\subsubsection{Polynomial Regression Modelling and Prediction of Antioxidant Activity}

The predictions and validation for all experimental data of each osmotic agent are summarized in the Table 5. The predicted values were determined by the polynomial model of $y=p_{1} x^{2}+$ $\mathrm{p}_{2} \mathrm{x}+\mathrm{p}_{3}$ with $95 \%$ confidence interval, where $\mathrm{p}_{3}$ is the constant that fixes the response at a given concentration and temperature of the experiment, $\mathrm{p}_{2}$ and $\mathrm{p}_{1}$ are the regression coefficients for the polynomial interaction effect terms and $\mathrm{x}$ is the relationship between the independent variables (sucrose, $\mathrm{NaCl}$ and $\mathrm{AgNPs}$ ). The coefficients for the linear quadratic terms of antioxidant activities for AgNPs are presented in Fig. 5a,b. The modelling effect of concentrations on the antioxidant activities in terms of the temperatures at which the antioxidant improved was found to improve by increasing amounts for each unit increase in temperature and concentration through a quadratic model of the form: fitpoly $4(x)=p_{1} x^{2}+p_{2} x+p_{3}$.

The predicted quadratic models for antioxidant activities are shown in Equations 8, 9 and 10 for sucrose, $\mathrm{NaCl}$ and AgNPs, respectively.

In the analysis of the predicted models, good coefficients of determination were obtained for each of antioxidant activity (sucrose $\mathrm{R}^{2}=0.87 ; \mathrm{NaCl} \mathrm{R}^{2}=0.89 ; A g N P s \mathrm{R}^{2}=0.91$ ) where the model explained most of the observed variations (Table 6). This shows that antioxidant activity forecasting for AgNPs is excellent while for $\mathrm{NaCl}$ and sucrose is very good. ${ }^{38}$ Significant $(P<0.05)$ quadratic effects of different concentrations at different temperatures were observed. The model $P$-values of antioxidant activities of the three solutions were less than 0.05 which implies that the model is significant.

$$
\begin{aligned}
& -1.158 e-06 x^{2}+0.01481 x+19.69 \\
& -4.746 e-08 x^{2}+0.002405 x+26.47 \\
& -1.28 e-06 x^{2}+0.02289 x+15.64
\end{aligned}
$$

\subsubsection{Response Surface Analysis of Antioxidant Predictions}

Antioxidant activity was significantly affected by the concentrations and temperatures of osmotic solutions with $P<0.05$ for linear, quadratic and interactive effects. There are marginal increases in predicted values (Table 6), which are close to the experimental values. The effects of the variables and their interaction on antioxidant activities are shown in Fig. 6a-c. Concentrations of sucrose, $\mathrm{NaCl}$ and AgNPs increased in positive proportion, hence it had a significant influence on the antioxidant properties of OD tomato slices

\subsection{Effects of Osmotic Agents and Solution Temperatures on} the Fungal Growth of Osmotically Dehydrated Tomato Slices

The result of OD temperatures on fungal growth is presented in Fig. 7. The number of fungal isolates reduced with increase in temperature implying that the fungal isolates were temperature sensitive. No growth was observed on nutrient agar for all OD tomato slices with sucrose, sodium chloride and silver nanoparticles after incubation at $37^{\circ} \mathrm{C}$ for $24 \mathrm{~h}$. For PDA plates, fungal growth was observed two days after incubation for slices dehydrated with sucrose solution and control. The growth appeared on the fifth and seventh day after incubation for sodium chloride and silver nanoparticles, respectively. Plates showing fungal isolates are shown in Fig. 8. OD samples with sucrose were found to be least effective because growth was found just two days after inoculation followed by sodium chloride in which growth was observed five days after inoculation. This is in line with the findings of Manafi et al. ${ }^{43}$ that using salt solutions as osmotic media have advantages over sucrose because it has low

\begin{tabular}{|c|c|c|c|c|c|c|c|}
\hline \multirow[t]{2}{*}{ Conc. } & \multirow[t]{2}{*}{ Temp. } & \multicolumn{2}{|c|}{ Sucrose } & \multicolumn{2}{|c|}{$\mathrm{NaCl}$} & \multicolumn{2}{|c|}{ AgNPs } \\
\hline & & Experimental value & Predicted value & Experimental value & Predicted value & Experimental value & Predicted value \\
\hline 75 & 60 & 71.17 & 72.25 & 42.28 & 42.99 & 88.31 & 89.00 \\
\hline 75 & 70 & 68.01 & 69.06 & 42.39 & 43.07 & 84.68 & 85.43 \\
\hline 75 & 80 & 57.17 & 57.98 & 41.20 & 42.62 & 80.01 & 80.89 \\
\hline 50 & 60 & 66.99 & 67.02 & 41.62 & 41.88 & 80.42 & 81.31 \\
\hline 50 & 70 & 67.69 & 68.21 & 34.98 & 35.05 & 75.52 & 76.29 \\
\hline 50 & 80 & 50.48 & 51.22 & 35.84 & 36.32 & 46.71 & 47.65 \\
\hline 25 & 60 & 60.72 & 60.86 & 41.22 & 42.94 & 46.67 & 47.77 \\
\hline 25 & 70 & 58.50 & 59.02 & 28.06 & 28.88 & 30.33 & 32.03 \\
\hline 25 & 80 & 30.93 & 31.11 & 27.65 & 28.23 & 27.04 & 28.67 \\
\hline
\end{tabular}
viscosity and their ions diffuse better due to smaller sizes which

Table 5 The experimental and predicted values of concentration and temperature for the three antioxidants. 

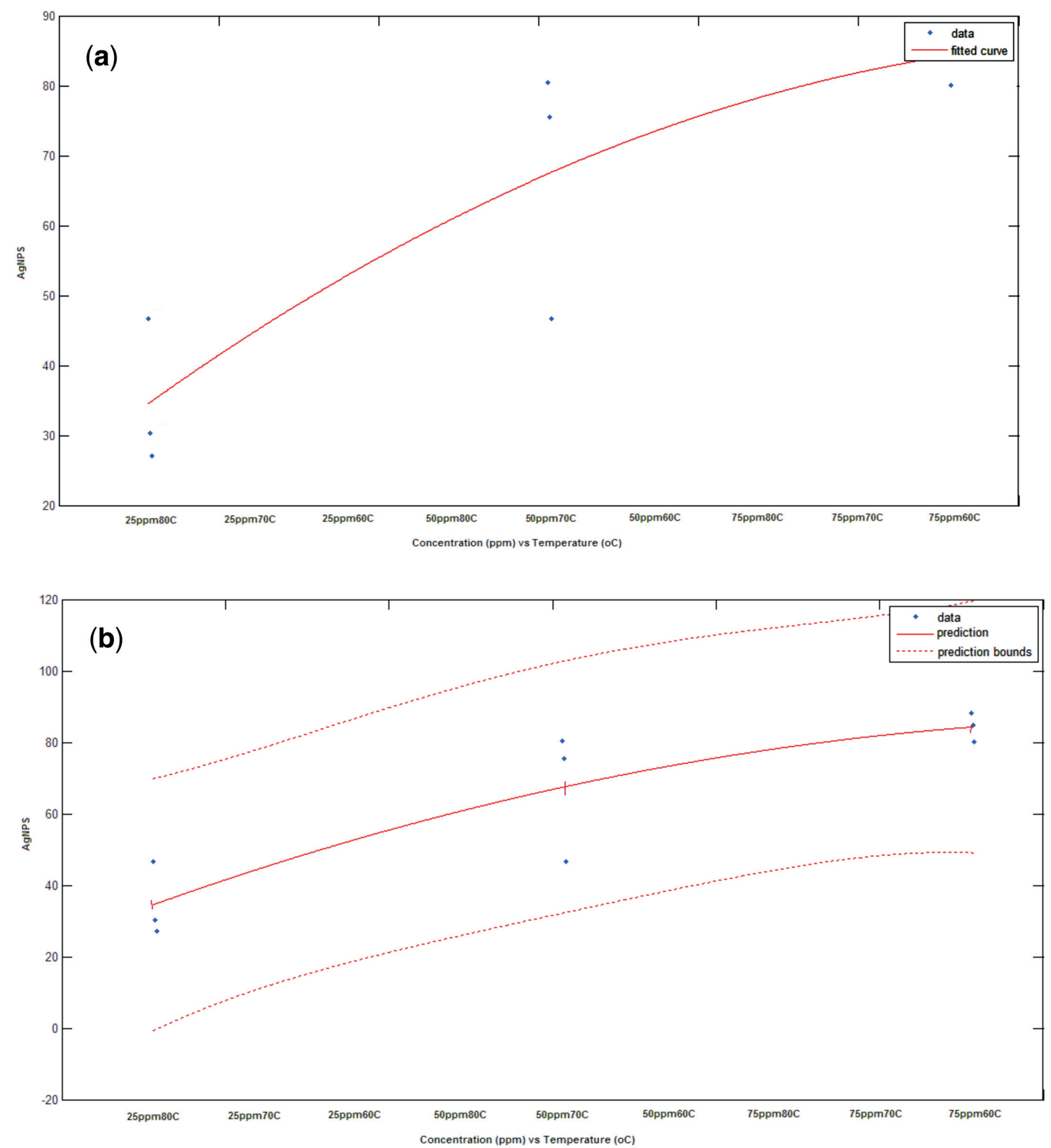

Figure 5 (a) Polynomial regression modelling of antioxidant activity in OD using AgNPs. (b) Polynomial regression fitted line plot of antioxidant activity in OD using AgNPs.

also account for more water loss than sucrose. OD samples with AgNPs were found to be most effective, having the highest inhibitory effect because growth was found on the seventh day of inoculation. This is an indication that OD tomato slices with AgNPs can extend shelf life of tomato samples longer than sucrose and $\mathrm{NaCl}$ which are known osmotic dehydration solutions. This is similar to the findings of Kabir et al. ${ }^{46}$ which reported that 50 and 100 ppm AgNPs had significant inhibitory effect against powdery mildew (a disease caused by fungi) in tomatoes.

\subsubsection{Microbial Community in Treated Tomato Slices}

The number of fungal isolates as determined in the osmotically dehydrated tomato slices using sucrose, sodium chloride and silver-nanoparticles is presented in Fig. 9. A total of 20 fungal isolates were obtained from all the samples. Seven isolates were obtained from samples osmotically dehydrated with sucrose and the isolates covered four genera, namely Aspergillus spp., Trichoderma spp., Penicillium spp. and Rhizopus spp. with Trichoderma spp. occurring most. Six isolates were obtained from samples osmotically dehydrated with sodium chloride and the isolates covered two genera namely Curvularia spp. and Aspergillus spp. with Aspergillus niger occurring most. Four isolates were obtained from samples osmotically dehydrated with AgNPs and the isolates covered two genera, namely Aspergillus spp. and Penicillium spp. with Aspergillus niger also occurring most and three isolates were found in the control sample and the isolates covered two genera, namely Aspergillus 

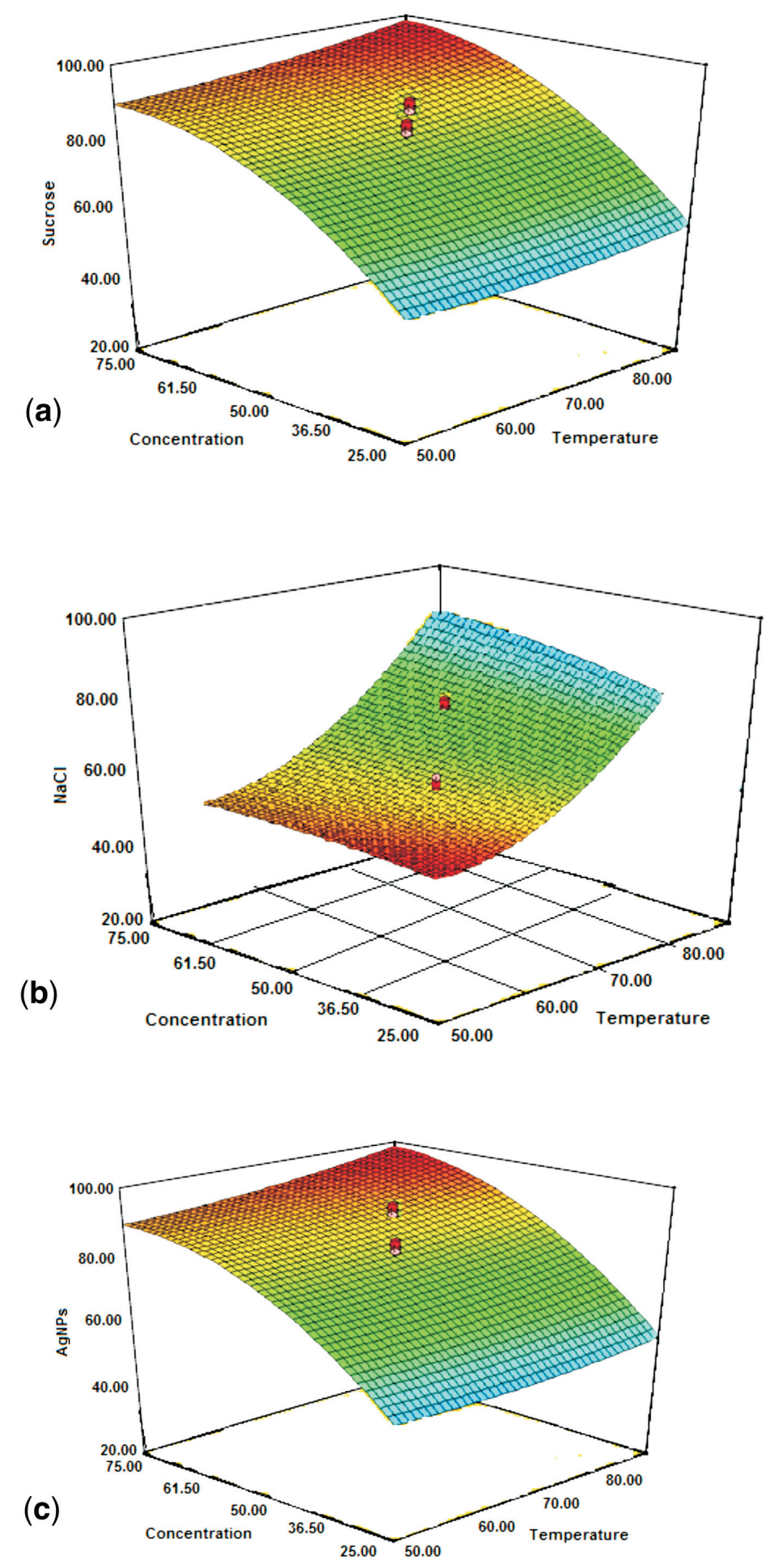

Figure 6 (a) Response surface for antioxidant activity of OD tomatoes using sucrose. (b) Response surface for antioxidant activity of OD tomatoes using $\mathrm{NaCl}$. (c) Response surface for antioxidant activity of OD tomatoes using AgNPs.

niger and Rhizopus spp. However, no growth was obtained on the nutrient agar plates. This implies that there was no bacterial growth on the tomato osmotically dehydrated with the three dehydrating agents used in this study. In all, five fungal genera were isolated from osmotically dehydrated tomato slices, namely: Aspergillus spp., Trichoderma spp., Rhizopus spp., Curvularia spp. and Penicillium spp. This is in consonance with the results of Ibrahim et al. ${ }^{7}$, Baker ${ }^{47}$, Akinmusire ${ }^{48}$, Wogu and Ofuase $^{49}$ and Abdel-Mallek et al..$^{50}$ that reported Aspergillus niger, Rhizopus spp. and Penicillum spp. as the major fungi responsible for rottenness of tomatoes and the production of volatile compounds in rotten tomatoes. Most of the fungi isolated in this study could be sources of potent mycotoxins which are detrimental to health. This is agreement with the reports of Ibrahim et al. ${ }^{7}$ that Aspergillus niger is a source of ochratoxin which is considered to be a potent carcinogen. As observed in this study, Aspergillus niger had the highest occurrence while Penicillium spp. and Curvularia spp. occurred least, which is in consonance with report of Onuorah and Orji ${ }^{9}$ that reported the dominance of Aspergillus niger in the fungal spoilage of 


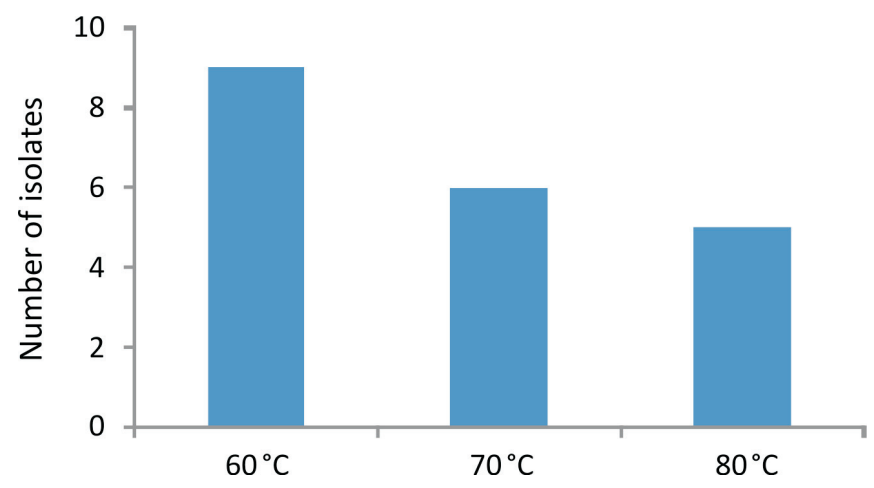

Figure 7 Fungal growth pattern of osmotically dehydrated tomato slices using sucrose, sodium chloride and silver nanoparticles against their temperatures.

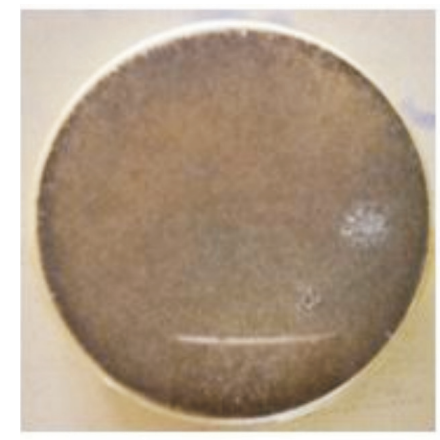

Rhizopus spp.

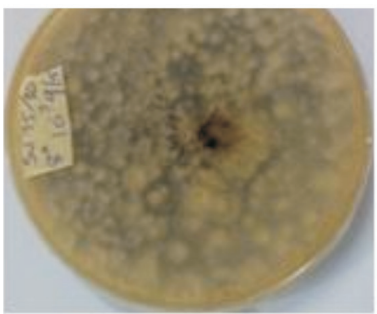

Aspergillus spp.

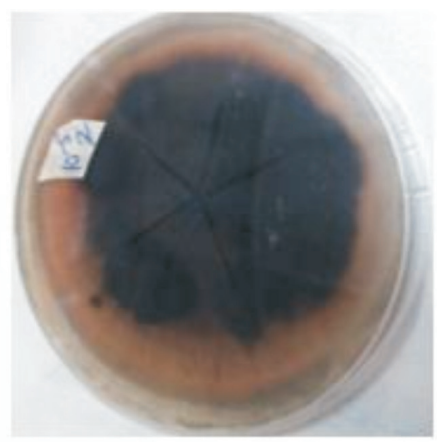

Curvularia spp,

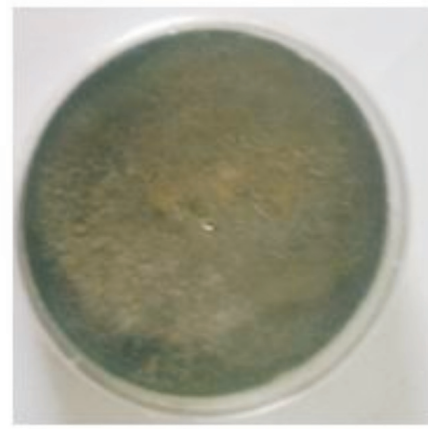

Trichoderma spp.

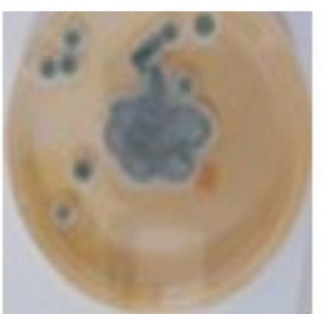

Penicillium spp.

Figure 8 Fungal isolates in tomato slices osmotically dehydrated.

post-harvest tomato fruits sold in major markets in Awka, Nigeria.

\section{Conclusion}

This study has comparatively investigated the use of AgNPs, sucrose and $\mathrm{NaCl}$ as osmotic solutions for the preservation of

tomato slices at different temperatures with different concentrations. AgNPs had the greatest influence in suppressing microbial growth, improved antioxidant activity, water loss, solid gain, water and solid diffusivities. Polynomial regression model and three-way ANOVA were successfully applied to model and determine statistical significance of osmotic conditions on anti-

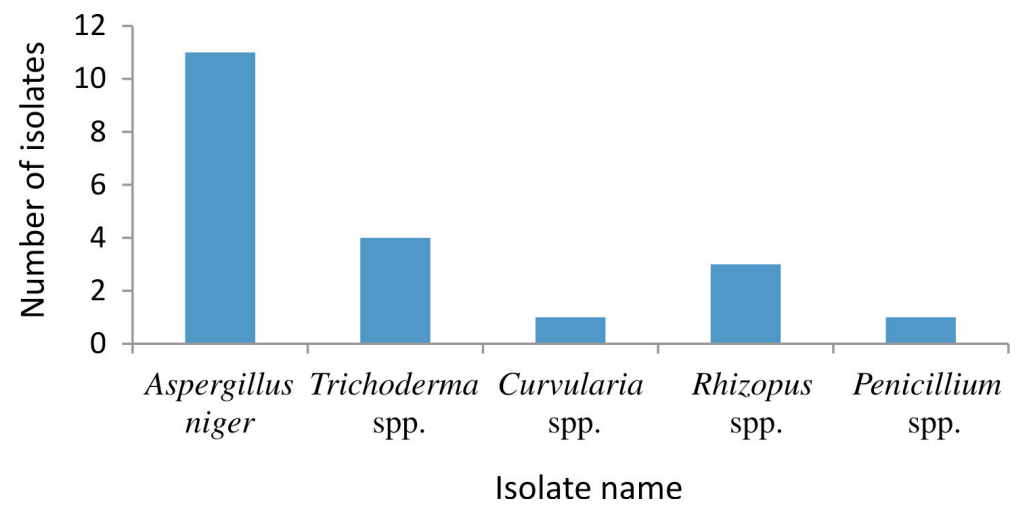

Figure 9 Number of fungal isolates in osmotically dehydrated tomato slices. 
oxidant activity, which showed that the effects were statistically significant.

\section{${ }^{s}$ ORCID iDs}

\section{Azeez: \\ A. Lateef: \\ orcid.org/0000-0002-6415-3490 \\ orcid.org/0000-0001-5302-9892}

\section{References}

1 E. Capanoglu, J. Beekwilder, D. Boyacioglu, R.C.H. De Vos and R.D. Hall, The effect of industrial food processing on potentially health-beneficial tomato antioxidants, Crit. Rev. Food Sci. Nutr., 2010, 50(10), 919-930.

2 W.C. De Abreu, P.M.B. De Fatima, V.E.V. Barros and E.P. da Silva, Total antioxidant activity of dried tomatoes marketed in Brazil, Int. J. Food Prop., 2014, 17(3), 639-649.

3 A. Ayari, N. Achir, A. Servent, J. Ricci and P. Brat, Development of a nutritional profile predicting tool for fresh and processed tomatobased products, Int. J. Food Sci. Technol., 2015, 50, 1598-1606.

4 L. Azeez, S.A. Adebisi, A.O. Oyedeji, R.O. Adetoro and K.O. Tijani, Bioactive compounds' contents, drying kinetics and mathematical modelling of tomato slices influenced by drying temperatures and time, J. Saudi Soc. Agric. Sci., 2017. http://dx.doi.org/10.1016/j.jssas.2017.03.002

5 L. Azeez, O.A. Oyedeji, S.A. Adebisi, A.L. Adejumo and K.O. Tijani, Chemical components retention and modelling of antioxidant activity using neural networks in oven dried tomato slices with and without osmotic dehydration pre-treatment, Food Measure., 2017, 11(4), 2247-2258.

6 P. Singh and G.K. Goyal, Dietary lycopene: its properties and anticarcinogenic effects, Comp. Rev. Food Sci. Food Safety, 2008, 7, 255-270.

7 A.D. Ibrahim, K. Musa, A. Sani, A.A. Aliero and B.S. Yusuf, Microorganisms associated with the production of volatile compounds in spoilt tomatoes, Res. Biotechnol., 2011, 2, 82-89.

8 L. Azeez, M.D. Adeoye, O.T. Ganiyu, I.O. Abdulsalami, T.A. Majolagbe and A.T. Lawal, Influence of microbial contamination on antioxidant composition and free radicals scavenging effects of fresh and decaying spices, Fountain J. Nat. Appl. Sci., 2012, 1(1), 55-64.

9 S. Onuorah and M.U. Orji, Fungi associated with the spoilage of post-harvest tomato fruits sold in major markets in Awka, Nigeria, Uni. J. Microbiol. Res., 2015, 3(2), 11-16

10 A. Ciurzynska, H. Kowalska, H. Czajkowska and A. Lenart, Osmotic dehydration in production of sustainable and healthy food, Trends Food Sci. Technol., 2016, 50, 186-192.

11 G.B. Martınez-Hernandez, M. Boluda-Aguilar, A. Taboada-Rodrıguez, S. Soto-Jover, F. Marın-Iniesta and A. Lopez-Gomez, Processing, packaging, and storage of tomato products: influence on the lycopene content, Food Eng. Rev., 2015. DOI: 10.1007/s12393-015-9113-3

12 E. Demiray and Y. Tulek, Degradation kinetics of $\beta$-carotene in carrot slices during convective drying, Int. J. Food Prop., 2016. DOI: 10.1080/10942912.2016.1147460

13 E.K. Dermesonlouoglou, S. Pourgouri and P.S. Taoukis, Kinetic study of the effect of the osmotic dehydration pre-treatment to the shelf life of frozen cucumber, Innov. Food Sci. Emerg. Technol., 2008, 9, 542-549.

14 A.K. Yadav and S.V. Singh, Osmotic dehydration of fruits and vegetables: a review, J. Food Sci. Technol., 2014, 51(9), 1654-1673.

15 S. Chandra1 and D. Kumari, Recent development in osmotic dehydration of fruit and vegetables: a review, Crit. Rev. Food Sci. Nutr. 2015, 55(4), 552-561.

16 I. Ahmed, I.M. Qazi and S. Jamal, Developments in osmotic dehydration technique for the preservation of fruits and vegetables, Innov. Food Sci. Emerg. Technol., 2016. DOI: 10.1016/j.ifset.2016.01.003

17 A. Rózek, I. Achaerandio, C. Güell, F. López and M. Ferrando, Grape phenolic impregnation by osmotic treatment: influence of osmotic agent on mass transfer and product characteristics, J. Food Eng., 2009, 94, 59-68.

18 G.D. Mercali, L.D.F. Marczak, I.C. Tessaro and C.P.Z. Noreña, Evaluation of water, sucrose and $\mathrm{NaCl}$ effective diffusivities during osmotic dehydration of banana (Musa sapientum, Shum.), LWT - Food Sci. Technol., 2011, 44, 82-91.

19 O.L. Fernandes, J.L.G. Correa, P.M.C. de Angelis, S.R.A. de Lemos and M.B. Vilela, Osmotic dehydration of yacon (Smallanthus sonchifolius): optimization for fructan retention, LWT - Food Sci. Technol., 2016, 71, 77-87.

20 A.P.M. Landim, M.I.M.J. Barbosa and J.L.B. Júnio, Influence of osmotic dehydration on bioactive compounds, antioxidant capacity, colour and texture of fruits and vegetables: a review, Ciência Rural, Santa Maria, 2016, 46(10), 1714-1722.

21 P. Sette, D. Salvatori and C. Schebor, Physical and mechanical properties of raspberries subjected to osmotic dehydration and further dehydration by air- and freeze-drying, Food Bioprod. Process., 2016, http://dx.doi.org/10.1016/j.fbp.2016.06.018

22 C.R.A. Suelen, E. Aguiar-Oliveira and R.R. Maldonado, Optimization of osmotic dehydration of pear followed by conventional drying and their sensory quality, LWT - Food Sci. Technol., 2016. DOI: 10.1016/j.lwt.2016.04.062

23 K.O. Falade, J.C. Igbeka and F.A. Ayanwuyi, Kinetics of mass transfer, and colour changes during osmotic dehydration of watermelon, J. Food Eng., 2007, 80, 979-985.

24 A. Ispir and I.T. Togrul, Osmotic dehydration of apricot: kinetics and the effect of process parameters, Chem. Eng. Res. Design, 2009, 87, 166-180.

25 S.M. Monnerat, T.R.M. Pizzi, M.A. Mauro and F.C. Menegalli, Osmotic dehydration of apples in sugar/salt solutions: concentration profiles and effective diffusion coefficients, J. Food Eng., 2010, 100, 604-612.

26 S. Bonatsou, V. Iliopoulos, A. Mallouchos, E. Gogou, V. Oikonomopoulou, M. Krokida, P. Taoukis and E.Z. Panagou, Effect of osmotic dehydration of olives as pre-fermentation treatment and partial substitution of sodium chloride by monosodium glutamate in the fermentation profile of Kalamata natural black olives, Food Microbiol., 2016.

DOI: $10.1016 / j . f m .2016 .11 .001$

27 J.L.G. Correa, D.B. Ernesto and K.S. de Mendonça, Pulsed vacuum osmotic dehydration of tomatoes: sodium incorporation reduction and kinetics modelling, LWT - Food Sci. Technol., 2016, 71, 17-24.

28 M.A. Azeez, A. Lateef, T.B. Asafa, T.A. Yekeen, A. Akinboro, I.C. Oladipo, E.B. Gueguim-Kana and L.S. Beukes, Biomedical applications of cocoa bean extract-mediated silver nanoparticles as antimicrobial, larvicidal and anticoagulant agents, J. Cluster Sci., 2017, 28(1), 149-164.

29 L. Azeez, A. Lateef and S.A. Adebisi, Silver nanoparticles (AgNPs) biosynthesized using pod extract of Cola nitida enhances antioxidant activity and phytochemical composition of Amaranthus caudatus Linn, Appl. Nanosci., 2017, 7(1-2), 59-66.

30 I.C. Oladipo, A. Lateef, M.A. Azeez, T.B. Asafa, T.A. Yekeen, A. Akinboro, A.S. Akinwale, E.B. Gueguim-Kana and L.S. Beukes, Green synthesis and antimicrobial activities of silver nanoparticles using cell-free extracts of Enterococcus species, Notulae Sci. Biol., 2017, 9(2), 196-203.

31 A. Lateef, S.A. Ojo, A.S. Akinwale, L. Azeez, E.B. Gueguim-Kana and L.S. Beukes, Biogenic synthesis of silver nanoparticles using cell-free extract of Bacillus safensis LAU 13: antimicrobial, free radical scavenging and larvicidal activities, Biologia, 2015, 70(10), 1295-1306.

32 A. Lateef, M.A. Azeez, T.B. Asafa, T.A. Yekeen, A. Akinboro, I.C. Oladipo, F.E. Ajetomobi, E.B. Gueguim-Kana and L.S. Beukes, Cola nitida-mediated biogenic synthesis of silver nanoparticles using seed and seed shell extracts and evaluation of antibacterial activities, BioNanoSci., 2015, 5(4), 196-205.

33 A. Lateef, M.A. Azeez, T.B. Asafa, T.A. Yekeen, A. Akinboro, I.C. Oladipo, L. Azeez, S.A. Ojo, E.B. Gueguim-Kana and L.S. Beukes, Cocoa pod husk extract-mediated biosynthesis of silver nanoparticles: its antimicrobial, antioxidant and larvicidal activities, J. Nanostructure Chem., 2016, 6(2), 159-169.

34 A. Lateef, M.A. Azeez, T.B. Asafa, T.A. Yekeen, A. Akinboro, I.C. Oladipo, L. Azeez, S.E. Ajibade, S.A. Ojo, E.B. Gueguim-Kana and L.S. Beukes, Biogenic synthesis of silver nanoparticles using a pod extract of Cola nitida: antibacterial and antioxidant activities and application as a paint additive, J. Taibah Uni. Sci., 2016, 10, 551-562.

35 A. Lateef, M.A. Akande, M.A. Azeez, S.A. Ojo, B.I. Folarin, E.B. Gueguim-Kana and L.S. Beukes, Phytosynthesis of silver nanoparticles (AgNPs) using miracle fruit plant (Synsepalum dulcificum) for antimicrobial, catalytic, anti-coagulant and thrombolytic applications, Nanotechnol. Rev., 2016, 5(6), 507-520. 
36 A. Lateef, M.A. Akande, S.A. Ojo, B.I. Folarin, E.B. Gueguim-Kana and L.S. Beukes, Paper wasp nest-mediated biosynthesis of silver nanoparticles for antimicrobial, catalytic, anti-coagulant and thrombolytic applications, 3Biotech., 2016, 6, 140.

37 Q. Tian, J. Chen and J. Dong, A method of constructing the fuel efficiency model based on quadratic polynomial regression, Procedia Eng., 2011, 15, 3749-3753.

38 E. Ostertagová, Modelling using polynomial regression, Adv. Control Eng. Infor. Sci. Procedia Eng., 2012, 48, 500-506.

39 W.P. Da Silva, C.M.P.D. Da Silva, A.J.E. De Farias and J.A.F. Da Silva, Osmotic dehydration and convective drying of coconut slices: experimental determination and description using one-dimensional diffusion model, J. Saudi Soc. Agric. Sci., 2014, 13, 162-168.

40 K.H. Domsch, W. Gams and T.H. Anderson, Paecilomyces, in: Compendium of Soil Fungi, Academic Press, London, 1980, 530-532.

41 M.M. Alam, M.N. Islam and M.N. Islam, Effect of process parameters on the effectiveness of osmotic dehydration of summer onion, Int. Food Res. J., 2013, 20(1), 391-396.

42 A.S. Abraao, A.M. Lemos, A. Vilela, J.M. Sousa and F.M. Nunes, Influence of osmotic dehydration process parameters on the quality of candied pumpkins, Food Bioprod. Process., 2013 http://dx.doi.org/10.1016/j.fbp.2013.04.006

43 M. Manafi, J. Hesari, H. Peighambardoust and M.A. RahimzadeKhoyi, Method for continuous kinetic evaluation of osmotic dehydration, LWT - Food Sci. Technol., 2010, 31(4), 317-321.

44 C. Singh, H.K. Sharma and B.C. Sarkar, Kinetics of mass transfer during convective dehydration of coated osmosed pineapple samples, J. Food Process. Eng., 2011, 34, 1879-1902.

45 S.M. Jafari, S.S. Jabari, D. Dehnad and S.A. Shahidi, Heat transfer enhancement in thermal processing of tomato juice by application of nanofluids, Food Bioprocess. Technol., 2016. DOI: 10.1007/s11947-016-1816-9

46 L. Kabir, K. Sang-Woo, J. Jing-Hee, K. Yun-Seo, K. Kyoung-Su and L. Youn-Su, The Taxonomy of the Powdery Mildew Fungi, The Powdery Mildews. A Comprehensive Treatise, APS Press, St. Paul, 2011, 13-55.
47 S. Baker, Aspergillus niger genomics: past, present and into the future. Med. Mycol., 2006, 44(1), S17-21.

48 O.O. Akinmusire, Fungi species associated with the spoilage of some edible fruits in Maiduguri, north eastern Nigeria, Adv. Environ. Biol., 2011, 5(1), 157-161.

48 M.D. Wogu and O. Ofuase, Microorganisms responsible for the spoilage of tomato fruits, Lycopersicum esculentum, sold in markets in Benin City, southern Nigeria, Scholars Acad. J. Biosci., 2014, 2(7), 459-466.

50 A.Y. Abdel-Mallek, S.K. Hemida and M.M.K. Bagy, Studies on fungi associated with tomato fruits and effectiveness of some commercial fungicides against three pathogens, Mycopathologia, 1995,130, 109-116.

51 N. Pradhan, S. Singh, N. Ojha, A. Shrivastava, A. Barla, V. Rai, and $\mathrm{S}$. Bose, Facets of nanotechnology as seen in food processing, packaging, and preservation industry, BioMed Res. Inter., 2015 http://dx.doi.org/10.1155/2015/365672

52 T. Singh, S. Shukla, P. Kumar, V. Wahlal, V.K. Bajpai and I.A. Rather, Application of nanotechnology in food science: perception and overview, Frontiers Microbiol., 2017, 8 DOI: 10.3389/fmicb.2017.01501

53 X. He and H. Hwang, Nanotechnology in food science: functionality, applicability, and safety assessment. J. Food Drug Anal., 2016, 24, 671-681.

54 D.J. McClements and H. Xiao, Is nano safe in foods? Establishing the factors impacting the gastrointestinal fate and toxicity of organic and inorganic food-grade nanoparticles. npj Sci. Food, 2017, 1(6) DOI: 10.1038/s41538-017-0005-1

55 M. Carbone, D.T. Donia, G. Sabbatella, R. Antiochia, Silver nanoparticles in polymericmatrices for fresh food packaging. J. King Saud Uni. Sci., 2016, 28, 273-279.

56 T.A. Yekeen, M.A. Azeez, A. Akinboro, A. Lateef, T.B. Asafa, I.C. Oladipo, S.O.Oladokun and A.A. Ajibola, Safety evaluation of green synthesized Cola nitida pod, seed and seed shell extracts-mediated silver nanoparticles (AgNPs) using Allium cepa assay.J. Taibah Uni. Sci., 2017, 11(6), 895-909.

http://dx.doi.org/10.1016/j.jtusci.2017.06.005 